Check for updates

Cite this: RSC Adv., 2019, 9, 15013

Received 22nd March 2019

Accepted 4th May 2019

DOI: 10.1039/c9ra02210d

rsc.li/rsc-advances

\section{Degradation and biocompatibility of a series of strontium substituted hydroxyapatite coatings on magnesium alloys}

\begin{abstract}
Xuenan Gu, (D) *ab Wenting Lin, ${ }^{a}$ Dan Li, ${ }^{a}$ Hongmei Guo, ${ }^{a}$ Ping Li (D) ab and Yubo Fan*abc
There has been a surge in the research on magnesium (Mg) alloys as a promising selection for biomaterials application. However, as a foremost drawback, the fast degradation of $\mathrm{Mg}$ alloys limits its clinical use. In this study, a series of $\mathrm{Sr}-\mathrm{HA}$ coatings with the Sr content ranging between 10-100\% were prepared on Mg alloys, in order to control the degradation and enhance the osteoblast response. Microstructure analysis indicated the formation of $\mathrm{Ca}_{10-x} \mathrm{Sr}_{x}\left(\mathrm{PO}_{4}\right)_{6}(\mathrm{OH})_{2}$ coatings with the thickness ranging between 28-35 $\mu \mathrm{m}$. The degradation results suggested that an increase in the $\mathrm{Sr}$ content in the coatings led to the decreasing degradation rate of the $\mathrm{Sr}-\mathrm{HA}$ coated $\mathrm{Mg} .100 \% \mathrm{Sr}-\mathrm{HA}$ coatings provided the best corrosion protective effect with nearly no hydrogen evolution during 10 days' immersion in Hank's solution. The in vitro cell biocompatibility was evaluated with MC3T3-E1 osteoblasts using the extract assay. In each case the released $\mathrm{Sr}$ affected the osteoblast proliferation and the expression of osteogenesis markers including, ALP, Col-I and RUNX2, in a Sr concentration-dependent manner. These results suggest that Sr-HA coating is a promising combination for controlling the degradation and enhancing the cytocompatibility of $\mathrm{Mg}$ alloys. The degradation and osteoblast response could be simply controlled through the adjustment of Sr content in the coatings.
\end{abstract}

\section{Introduction}

Magnesium (Mg) and its alloys show excellent compatibility with human bones in density, elastic modulus and compressive strength. ${ }^{1-3} \mathrm{Mg}$ is essential for human metabolism and is naturally present in bone tissue. In addition, $\mathrm{Mg}$ can be gradually degraded in the human body, which makes it a promising candidate for orthopedic implants. ${ }^{1,4,5}$ In spite of these unique benefits, $\mathrm{Mg}$ based implants are of limited use in clinical applications. The main disadvantage is the fast degradation in the physiological environment and the associated side effects, including gas bubbles, local alkalization, fast decay of strength. ${ }^{6-8}$

Applying biocompatible and protective coatings, such as hydroxyapatite (HA), which is the main inorganic component of bones and has been used for decades in medicine and dentistry, onto magnesium alloys is a practical option to control the biodegradation process. $^{8-11}$ HA coatings could reduce the degradation of magnesium alloys with certain amounts of success. ${ }^{8,12-15}$

\footnotetext{
${ }^{a}$ School of Biological Science and Medical Engineering, Beihang University, Beijing 100191, China.E-mail: xngu@buaa.edu.cn; yubofan@buaa.edu.cn

${ }^{b}$ Beijing Advanced Innovation Centre for Biomedical Engineering, Beihang University, Beijing, China

'National Research Center for Rehabilitation Technical Aids, Beijing 100176, China
}

Strontium (Sr) is believed to play an important role in the treatment of osteoporosis and enhancement of bone remineralization as it is associated with a reduction of bone resorption and an increase in the formation of new bone., ${ }^{7,16,17}$ It is well documented that the presence of $\mathrm{Sr}^{2+}$ ions has the dual benefit of promoting pre-osteoblastic cell replication and inhibiting the activity of osteoclasts. ${ }^{18-21}$ Strontium ranelate (Protelos ${ }^{\circledR}$, Servier) is currently used in the treatment of post-menopausal osteoporosis, although its prescription has been recently restricted to the acute medical cases because of cardiovascular side effects. ${ }^{22}$ Additionally, Sr can replace the lattice sites of Ca in HA to form a continuous solid-solution ( $\mathrm{Sr}, x-\mathrm{HA}, x$ is fraction of substitution) up to full substitution (Sr-apatite) with improved mechanical properties and biological performance. ${ }^{17,23-25}$ There have been intensive studies to incorporate Sr into HA cements ${ }^{16,26-28}$ or coatings ${ }^{24,29-32}$ for better bone response. Furthermore, the degradation and resulted osteoblast response of $\mathrm{Sr}, x$-HA exhibit a dose dependent behaviour. ${ }^{16,17} \mathrm{Sr}$ incorporating destabilizes the structure of HA and increased the solubility and degradation of $\mathrm{Sr}, x$-HA with $x \cdot{ }^{17}$ With variations in degradation rate of $\mathrm{Sr}, x$-HA, the micro-environment are thereby affected. Particularly Sr availability through degradation inevitably changes, which in turn influence the metabolic activity of osteoblasts.

The Sr doses would affect the properties of Sr-HA coatings such as microstructure, solubility, degradation and cell interaction with materials. Therefore, the main aim of the present 
study was to highlight the influence of Sr doses of Sr-HA coated $\mathrm{Mg}$ alloys on their morphology, in vitro degradation, osteoblast proliferation and differentiation.

\section{Materials and methods}

\subsection{Materials preparation}

AZ31B magnesium alloys were cut into $20 \times 10 \times 2 \mathrm{~mm}^{3}$ pieces, mechanically polished with SiC paper up to 2000 grit and cleaned ultrasonically with acetone, ethanol and deionized water for $5 \mathrm{~min}$ each. Prior to the electrodeposition, the samples were pre-treated with $40 \% \mathrm{HF}$ solution for activation, and then rinsed in distilled water and dried at room temperature.

\subsection{Electrodeposition}

The electrolyte for deposition was prepared by mixing a solution of $\mathrm{Ca}\left(\mathrm{NO}_{3}\right)_{2} \cdot 4 \mathrm{H}_{2} \mathrm{O}, \mathrm{Sr}\left(\mathrm{NO}_{3}\right)_{2}, \mathrm{NH}_{4} \mathrm{H}_{2} \mathrm{PO}_{4}, \mathrm{NaNO}_{3}$ and $\mathrm{H}_{2} \mathrm{O}_{2}$. The concentrations of $\mathrm{NH}_{4} \mathrm{H}_{2} \mathrm{PO}_{4}, \mathrm{NaNO}_{3}$ and $\mathrm{H}_{2} \mathrm{O}_{2}$ were $0.025 \mathrm{~mol} \mathrm{~L}^{-1}, 0.1 \mathrm{~mol} \mathrm{~L}^{-1}$ and $10 \mathrm{~mL} \mathrm{~L}^{-1}$. The $\mathrm{Ca}\left(\mathrm{NO}_{3}\right)_{2} \cdot 4 \mathrm{H}_{2} \mathrm{O}$, $\mathrm{Sr}\left(\mathrm{NO}_{3}\right)_{2}$ concentrations were adjusted so that the $\mathrm{Sr} /(\mathrm{Sr}+\mathrm{Ca})$ ratios of the electrolytes were $0 \%, 10 \%, 20 \%, 50 \%$, and $100 \%$, respectively. The temperature was maintained at $60{ }^{\circ} \mathrm{C}$ using water bath.

The electrodeposition was conducted in a standard electrolysis cell with three electrodes in which the AZ31B alloy, the graphite plate and a saturated calomel electrode (SCE) acting as working electrode, counter electrode and reference electrode, respectively. Deposition was performed at $-2.5 \mathrm{~V} / \mathrm{SCE}$ for $70 \mathrm{~min}$ through an electrochemical workstation (CHI660E). After deposition, the samples were further treated in $1 \mathrm{~mol} \mathrm{~L}^{-1}$ $\mathrm{NaOH}$ solution at $80{ }^{\circ} \mathrm{C}$ for $2 \mathrm{~h}$.

\subsection{Characterization}

The phase of Sr-HA coatings was analyzed using a Bruker D8 multipurpose X-ray diffractometer (XRD) with a scanning range $(2 \theta)$ of $20-70^{\circ}$, and a scanning speed of $4^{\circ} \min ^{-1}$. An environmental scanning electron microscopy (ESEM, FEI Quanta 250FEG) equipped with an energy dispersive spectrometry (EDS) was then used to examine the surface and cross-sectional morphology of the samples as well as the elemental compositions of the coatings.

\subsection{Immersion tests}

Immersion tests were carried out in Hank's solution $(8.00 \mathrm{~g}$ $\mathrm{NaCl}, 0.40 \mathrm{~g} \mathrm{KCl}, 0.14 \mathrm{~g} \mathrm{CaCl}_{2}, 0.35 \mathrm{~g} \mathrm{NaHCO}_{3}, 0.20 \mathrm{~g} \mathrm{\textrm {MgO } _ { 4 } ^ { - }}$ $\cdot 7 \mathrm{H}_{2} \mathrm{O}, 0.12 \mathrm{~g} \mathrm{Na} \mathrm{HPO}_{4} \cdot 12 \mathrm{H}_{2} \mathrm{O}, 0.06 \mathrm{~g} \mathrm{KH}_{2} \mathrm{PO}_{4}$ ) according to the ASTM-G31-72. The Mg samples were coated with Sr-HA coatings on all sides. The uncoated and Sr-HA coated samples were completely immersed in Hank's solution. The $\mathrm{pH}$ value was adjusted to $7.40 \pm 0.5$ and the temperature was maintained at $37 \pm 0.5{ }^{\circ} \mathrm{C}$. The hydrogen evolution behaviour was measured during the immersion. After 10 days immersion, the samples were removed from the solution, gently rinsed with distilled water, followed by drying at room temperature. Surface morphologies of the samples were analysed by ESEM and EDS. The ion concentrations were determined by inductively coupled plasma optical emission spectrometry (ICP-OES; Leeman, Profile).

\subsection{Electrochemical tests}

The electrochemical corrosion was carried out in Hank's solution using a CHI660E electrochemistry workstation. A threeelectrode cell was used for electrochemical measurements. The counter electrode was a platinum plate and the reference electrode was a saturated calomel electrode. The sample was pre-incubated in Hank's solution for $30 \mathrm{~min}$ to obtain a relatively steady open circuit potential (OCP). Afterwards, the potentiodynamic polarization test was conducted with a scan rate of $1.0 \mathrm{mV} \mathrm{s}^{-1}$ with the initial potential at about $300 \mathrm{mV}$ below the OCP.

\subsection{Osteoblast proliferation}

The proliferation of osteoblast-like cells (MC3T3-E1, ATCC CRL2593) was evaluated using Cell Counting Kit-8 (CCK-8, Dojindo) assay according to standard ISO 10993-5. Prior to the cell experiments, samples were sterilized using ultraviolet radiation for at least $2 \mathrm{~h}$. Extracts were prepared with a surface area to Dulbecco's modified Eagle's medium (DMEM, low glucose, Gibco) ratio of $1 \mathrm{~mL} \mathrm{~cm}^{-2}$ in a humidified atmosphere with $5 \%$ $\mathrm{CO}_{2}$ at $37{ }^{\circ} \mathrm{C}$ for $72 \mathrm{~h}$ incubation. The extract was centrifuged twice, and then the supernatant solution was withdrawn and filtered with milipore filters $(0.22 \mu \mathrm{m})$. The $\mathrm{pH}$ values and osmolality of the extracts were measured. Ion concentrations were determined by ICP-OES. The extract was diluted to $50 \%$.

MC3T3-E1 were cultured in DMEM, 10\% fetal bovine serum (FBS, Gibco), $100 \mathrm{U} \mathrm{mL}^{-1}$ penicillin and $100 \mu \mathrm{g} \mathrm{mL} \mathrm{m}^{-1}$ streptomycin at $37{ }^{\circ} \mathrm{C}$ in a humidified atmosphere of $5 \% \mathrm{CO}_{2}$. Cells were seeded in 96-well cell culture plates at $3 \times 10^{4}$ cells per $\mathrm{mL}$ and incubated for $24 \mathrm{~h}$ to allow attachment. The medium was then replaced with different extracts. After 1, 3 and 5 days, the extracts were replaced with DMEM, to which was then added $10 \%$ CCK- 8 solution. After incubation for a further $3 \mathrm{~h}$, the absorbance was read at $450 \mathrm{~nm}$ by a microplate reader (Varioskan LUX, Thermo), and expressed as the optical density (OD). Cell morphologies were observed by fluorescence staining. Cells were fixed with $4 \%$ polyoxymethylene and permeabilized with $0.1 \%$ Triton X-100. Cellular actin and nuclei were stained with FITC phalloidin and DAPI simultaneously before observing by a fluorescence microscope (Olympus).

\subsection{ALP activity}

MC3T3-E1 cells were seeded at a density of $3 \times 10^{4}$ cells per $\mathrm{mL}$ and incubated for $24 \mathrm{~h}$, at which time the medium was replace with the extracts. After 5 days, the cells were lysed in $0.2 \mathrm{~mL}$ of $0.1 \%$ Triton $\mathrm{X}-100$, shaken and conducted two standard freezethaw cycles. The alkaline phosphatase (ALP) activities were determined by a colorimetric assay using an ALP assay kit (Beyotime) and the absorbance was measured at $405 \mathrm{~nm}$. The intracellular total protein levels were determined using the bicinchoninic acid (BCA) protein assay kit (Beyotime) simultaneously. The ALP activity was finally normalized to the total 
protein content correspondingly and was expressed as $\mu \mathrm{mol} \mathrm{min}^{-1} \mathrm{mg}^{-1}$ protein.

\subsection{Real-time PCR assay (QPCR)}

MC3T3-E1s were cultured in 6-well plates at $5 \times 10^{5}$ cells per well and incubated for $24 \mathrm{~h}$. The medium was then replaced with $2 \mathrm{~mL}$ extracts and incubated for 5 days. Total RNA was extracted by using Trizol reagent (Gibco) and used as template $(2 \mu \mathrm{g})$ for reverse-transcribed into cDNA according to the manufacturer's instructions (Takara). To detect gene expression, quantitative real-time polymerase chain reaction (QPCR) was performed using the SYBR Premix Ex Taq kit (Takara, Shiga, Japan) according to the manufacturer's instructions and an iQ5 quantitative real-time PCR System (Bio-Rad Laboratories, Berkeley, CA). Forward and reverse primer sequences of alkaline phosphatase (ALP), collagen type I (COL-1) and runt-related transcription factor 2 (RUNX2) are shown in Table 1. All reactions were pre-denatured at $95{ }^{\circ} \mathrm{C}$ for $3 \mathrm{~min}$, followed by 40 cycles at $95{ }^{\circ} \mathrm{C}$ for $10 \mathrm{~s}$ and $55^{\circ} \mathrm{C}$ for $30 \mathrm{~s}$. After the PCR reaction, a melting curve was generated to confirm the PCR product's specificity and identity. Triplicate reactions were performed, and the relative fold-change of gene expression was determined by normalizing to GAPDH and calculating the $2^{-\Delta \Delta C_{\mathrm{T}}}$.

\subsection{Statistical analysis}

All data were expressed as means \pm standard deviation. Statistical analysis was conducted by one-way analysis of variance (ANOVA). A $p$ value of less than 0.05 was considered to be significant.

\section{Results and discussion}

\subsection{Coating characterization}

Fig. 1 depicts the XRD spectra of the Sr-HA coatings on $\mathrm{Mg}$ alloys. XRD results demonstrate the formation of $\mathrm{Ca}_{10-x} \mathrm{Sr}_{x}(-$ $\left.\mathrm{PO}_{4}\right)_{6}(\mathrm{OH})_{2}$ phase in all coatings, with the peaks corresponding closely to those of hydroxyapatite (JCPDS no: 72-1243) and pure strontium hydroxyapatite (JCPDS no: 70-1511). The diffraction peaks shift to lower $2 \theta$ values with increasing amount of $\mathrm{Sr}$ addition in the Sr-HA coatings, which is attributed to the larger ionic radius of Sr. ${ }^{17,22}$ The crystallinity of Sr-HA phase deteriorates with increasing $\mathrm{Sr}$ up to $50 \%$, as judged by the broaden diffraction peaks. When the Ca is completely substituted by $\mathrm{Sr}$, $\mathrm{Sr}_{5}\left(\mathrm{PO}_{4}\right)_{3}(\mathrm{OH})$ is formed and the crystallinity increases again evidenced by the sharp XRD peaks.

The Sr-HA coatings show similar FTIR spectra (Fig. 2). The characteristic peaks due to $\mathrm{PO}_{4}{ }^{3-}$ are clearly seen at $1025 \mathrm{~cm}^{-1}$,
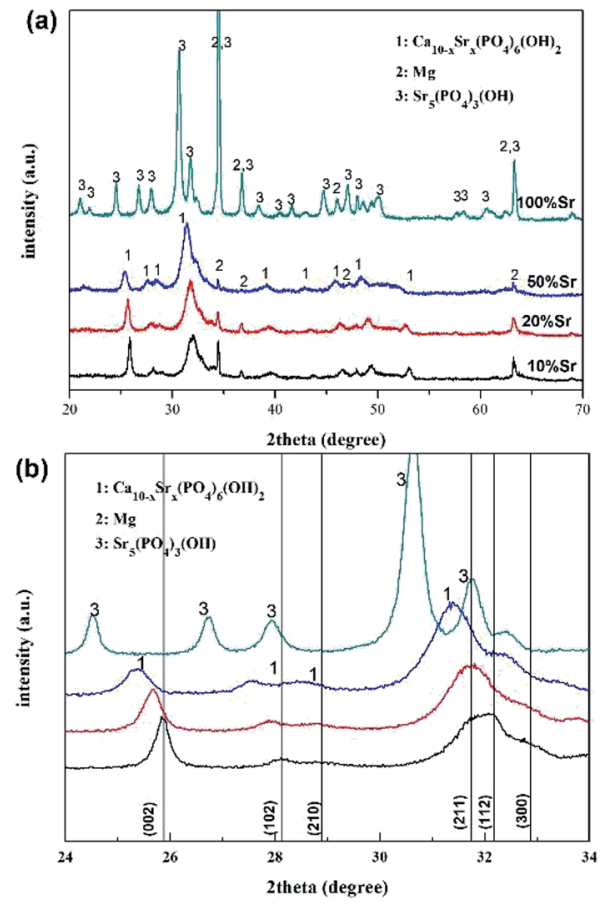

Fig. 1 XRD patterns of the Sr-HA coatings obtained from the electrolytes with $\mathrm{Sr} /(\mathrm{Sr}+\mathrm{Ca})$ ratios ranging $10-100 \%$. (a) Full diffraction spectra $\left(20-70^{\circ}\right)$ and $(b)$ detailed spectra $\left(24-35^{\circ}\right)$ of XRD patterns.

$600 \mathrm{~cm}^{-1}$ and $569 \mathrm{~cm}^{-1} .{ }^{22}$ The differentiation between various coatings locates in the carbonate adsorption band at around 1351-1540 $\mathrm{cm}^{-1},{ }^{33}$ the intensity of which increases with increasing $\mathrm{Sr}$ content up to $50 \%$. For $100 \% \mathrm{Sr}$ substitution, the intensity of the carbonate band is significantly reduced. In addition, the bands located at $3442 \mathrm{~cm}^{-1}$ and $1643 \mathrm{~cm}^{-1}$ are attributed to the stretching and bending mode of adsorbed water $\left(\mathrm{H}_{2} \mathrm{O}\right)$ molecules. ${ }^{22}$ The absorbed water molecules are bonded with the surface phosphate groups and form an amorphous hydrated layer. ${ }^{34}$ The increasing peak intensity is also observed with increasing Sr up to $50 \%$ and is reduced for $100 \%$ Sr-HA coating.

The surface morphologies of the coatings with different $\mathrm{Sr}$ contents are shown in Fig. 3. When the Sr content varies in the range of $10-50 \%$, the coatings are constituted by small size spheroids and exhibit some apparent porosity (Fig. 3a1-c1). The coating with $50 \%$ Sr exhibits more compact, uniform surface morphology. For $100 \%$ Sr-HA coating, it is composed of well packed flower-like crystals (see Fig. 3d1). The atomic strontium proportion is quantified by EDS for each coating to determine the substitution percentage by calculating the $\mathrm{Sr} /(\mathrm{Ca}+\mathrm{Sr})$ ratio

Table 1 Primer sequence for quantitative real-time PCR

\begin{tabular}{lll}
\hline Gene & Forward primer sequence $5^{\prime}-3^{\prime}$ & Reverse primer sequence $5^{\prime}-3^{\prime}$ \\
\hline ALP & AACGTGGCCAAGAACATCATCA & TGTCCATCTCCAGCCGTGTC \\
COL-1 & GCCTCCCAGAACATCACCTA & GCAGGGACTTCTTGAGGTTG \\
RUNX2 & CCATAACGGTCTTCACAAATCCT & TCTGTCTGTGCCTTCTTGGTTC \\
GAPDH & GGCACAGTCAAGGCTGAGAATC & ATGGGTGGTGAAGACGCCAGTA
\end{tabular}




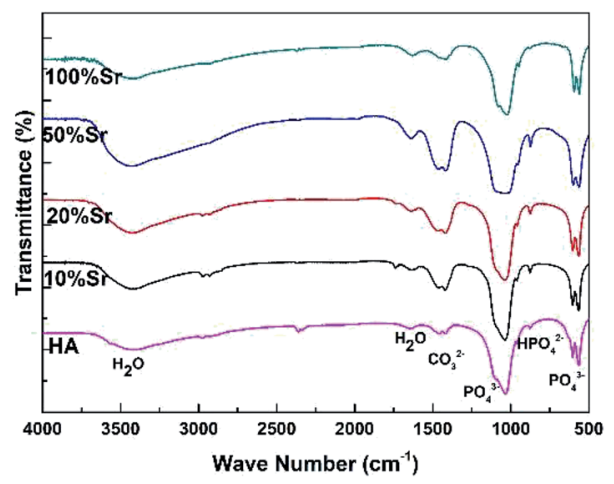

Fig. 2 FTIR spectra of the Sr-HA coatings obtained from the electrolytes with $\mathrm{Sr} /(\mathrm{Sr}+\mathrm{Ca})$ ratios ranging $10-100 \%$.

(Fig. 3e) and $(\mathrm{Ca}+\mathrm{Sr}) / \mathrm{P}$ ratio (Fig. 3f). The obtained coating contains a lower strontium content than the designated $\mathrm{Sr} /(\mathrm{Sr}+$ $\mathrm{Ca})$ ratio in the electrolyte. They have the $(\mathrm{Ca}+\mathrm{Sr}) / \mathrm{P}$ ratios of ranging from 1.73 to 1.82 for $10-50 \%$ Sr substituted Sr-HA coating. The higher $(\mathrm{Ca}+\mathrm{Sr}) / \mathrm{P}$ ratio can possibly be explained by the carbonate substitution in the apatite lattice (Fig. 2), which has been observed previously for carbonated HA. ${ }^{17,35}$ Fig. $4 \mathrm{a}$ and $\mathrm{b}$ shows the typical cross-section morphology and elements profiles of the coating. The coating thickness ranges from $28-35 \mu \mathrm{m}$. No apparent interface gap between the coating and magnesium substrate is observed, indicating the coating adhere well on the substrate.

\subsection{In vitro degradation}

The primary concern of these Sr-HA coatings is their protection efficacy of magnesium degradation. Thus the in vitro degradation of the experimental samples was characterized as a function of immersion time in Hank's, as shown in Fig. 5. The hydrogen evolution volume and the amount of $\mathrm{Mg}$ ions released decrease with increasing Sr content (Fig. 5a and c). The increment of $\mathrm{pH}$ values is significantly slowed down with Sr-HA coating. The $\mathrm{pH}$ increases to 10.0 after $5 \mathrm{~d}$ immersion for 10$50 \%$ Sr-HA coated samples. While for $100 \%$ Sr-HA coated samples, the $\mathrm{pH}$ only increases 9.0 after $10 \mathrm{~d}$ immersion in Hank's solution (Fig. 5b). The potentiodynamic polarization curves and the corresponding electrochemical parameters are shown in Fig. 6. It is evident that anodic kinetics of all the Sr-HA coated samples had been reduced, with the anodic polarization current approximately one order of magnitude lower than the uncoated $\mathrm{Mg}$. The restrictive effect on anodic kinetics leads to more noble corrosion potential for the coated samples compared with the uncoated control, indicating the coatings provide protection from corrosion. The calculated corrosion current density values are a function of the $\mathrm{Sr} /(\mathrm{Sr}+\mathrm{Ca})$ ratio in the coatings. The $100 \% \mathrm{Sr}-\mathrm{HA}$ coating reduced the corrosion current density to $17.55 \mu \mathrm{A} \mathrm{cm}{ }^{-2}$, a $\sim 53 \%$ reduction as compared to the $10 \%$ Sr-HA coated sample and a $\sim 93 \%$ reduction as compared to the uncoated sample. As such, the $\mathrm{Sr}$ content has a critical influence on the corrosion protectiveness, in which the $100 \%$ Sr-HA coating demonstrates the best inhibiting ability from corrosion (Fig. 5d).

After $10 \mathrm{~d}$ immersion in Hank's solution, the SEM observations indicate fewer small-sized spheroids for $10 \% \mathrm{Sr}-\mathrm{HA}$ coatings after immersion than the as-prepared coatings. Massive laminar precipitation is deposited and show denser coating morphology, while some micro cracks are still visible (Fig. 3a2). The EDS reveals that the Sr proportions in the coatings slightly increase to 7.4 at\% (Fig. 3e). 50\% Sr-HA coatings exhibit much

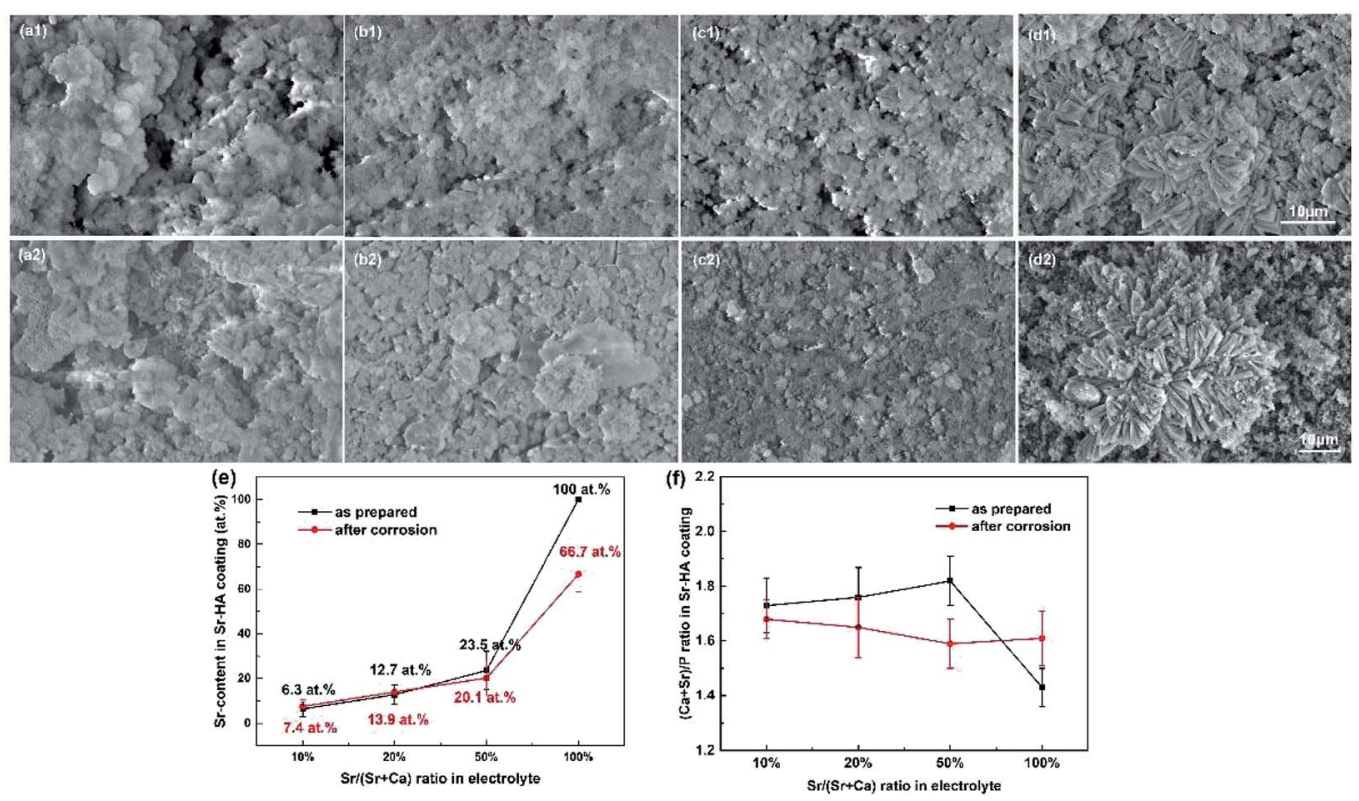

Fig. 3 Surface observations of the Sr-HA coatings with various $\mathrm{Sr} /(\mathrm{Sr}+\mathrm{Ca}$ ) ratios of (a1) $10 \%$, (b1) $20 \%$, (c1) $50 \%$, (d1) 100\%. (a2-d2) The surface morphologies of the coatings after immersion in Hank's solution for $10 \mathrm{~d}$. (e) The obtained $\mathrm{Sr} /(\mathrm{Sr}+\mathrm{Ca})$ ratio and (f) the (Ca $+\mathrm{Sr}) / \mathrm{P}$ ratio of the coatings before and after immersion tests. 


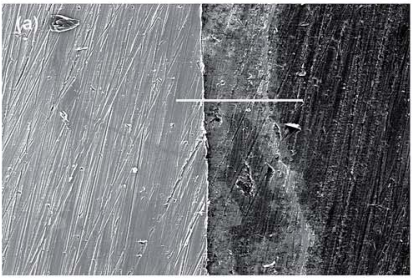

(b)
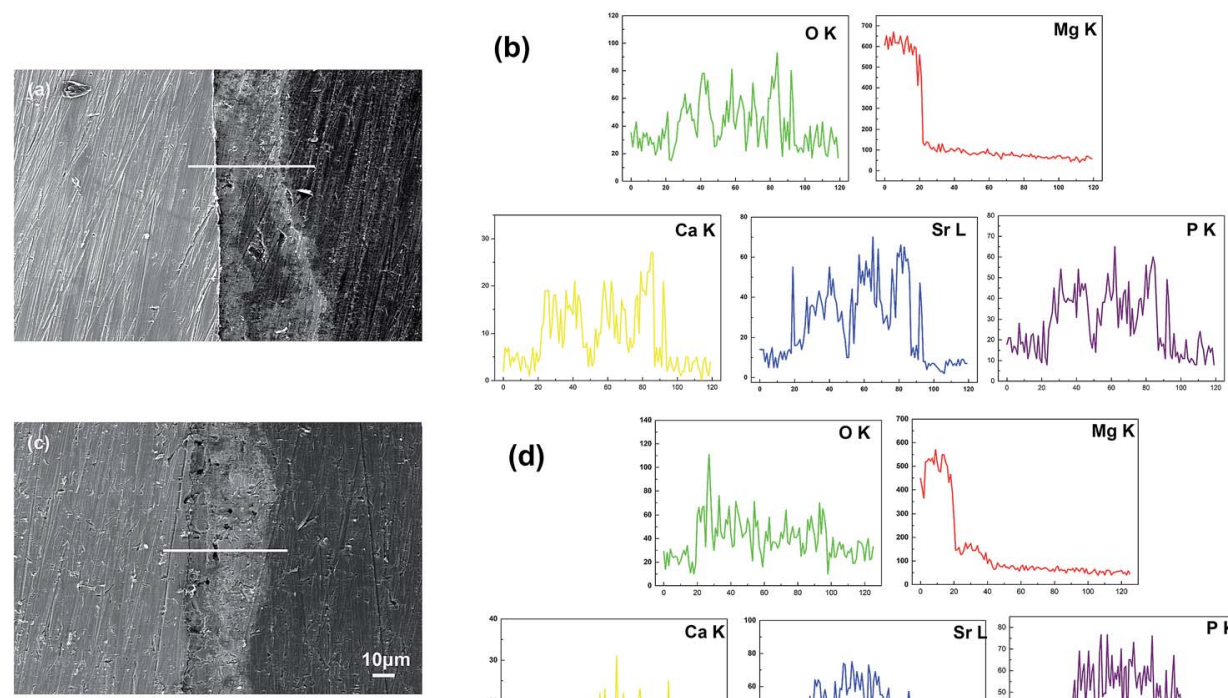

(d)
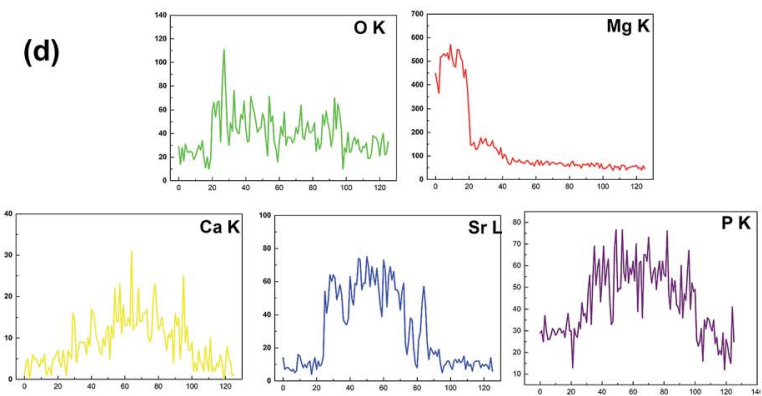

Fig. 4 The cross-sectional observations of the Sr-HA coatings with $50 \% \mathrm{Sr}$ (a) before and (c) after immersion in Hank's solution for $10 \mathrm{~d}$. The EDS line-scan of the $50 \% \mathrm{Sr}-\mathrm{HA}$ coating (b) before and (d) after corrosion.
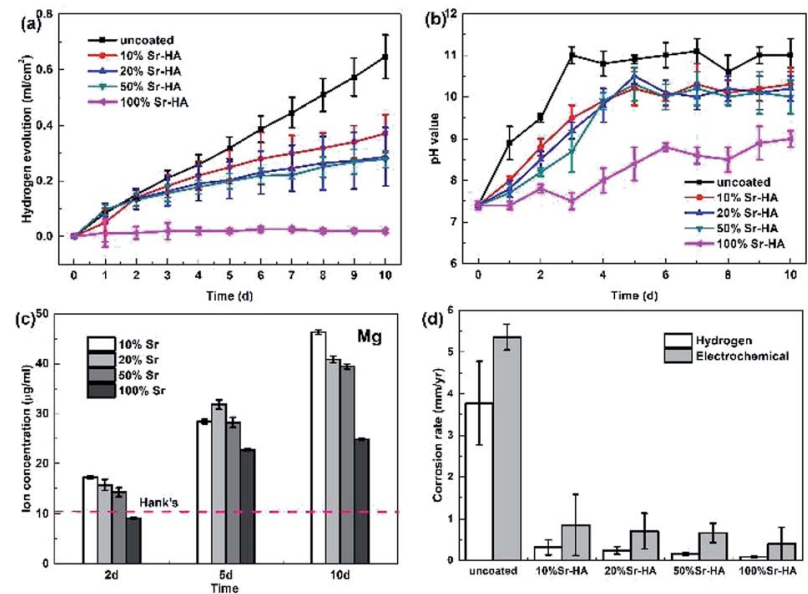

Fig. 5 (a) Hydrogen evolution, (b) $\mathrm{pH}$ change and (c) Mg releasement of the $\mathrm{Sr}-\mathrm{HA}$ coated $\mathrm{Mg}$ alloys immersed in Hank's solution. (d) The corrosion rates calculated from the electrochemical and immersion tests.

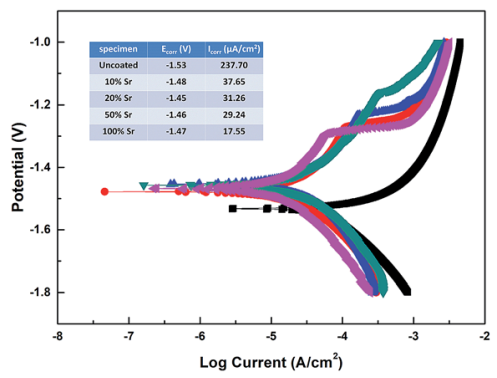

Fig. 6 Potentiodynamic polarization curves of the Sr-HA coated Mg alloys in Hank's solution. more compact surface morphology with the decreasing values of Sr content in the coating. The flower-like crystals are still seen on the surface of $100 \%$ Sr-HA coating with some loose cotton like precipitation in the surrounding area (Fig. 3d2). The $\mathrm{Sr}$ content is significantly reduced to 66.7 at $\%$. It is also found that the $(\mathrm{Ca}+\mathrm{Sr}) / \mathrm{P}$ ratio is reduced for $10-50 \%$ Sr-HA coating after immersion test, while it increases from 1.43 to 1.59 for $100 \% \mathrm{Sr}$ HA sample (Fig. 3f). From the cross-sectional images of the samples, some micro-pores appear in the coatings and a reduction of $\mathrm{Sr}$ content is observed in the outer layer in the coatings (Fig. 4c and d), indicating the dissolution of Sr-HA coating. The XRD analysis reveals no difference in the coatings before and after immersion tests (Fig. 7). We observe a reduction of the diffraction peaks from $\mathrm{Mg}$ substrate, indicating the coatings become more compact. This speculation is in line with the SEM observation in Fig. 3a2-d2. An interesting point to be noted is that there is no $\mathrm{Mg}(\mathrm{OH})_{2}$ peaks in the XRD diffraction spectra. It suggests that the Sr-HA coating could maintain its corrosion resistance and keep the $\mathrm{Mg}$ substrate nearly unattacked during the 10 days immersion test.

The $\mathrm{Ca}, \mathrm{Sr}$ and $\mathrm{P}$ releasement for different immersion intervals is revealed in Fig. 8. With increasing designed $\mathrm{Sr}$ proportions up to $50 \%$, the increasing concentrations of $\mathrm{Sr}$ and $\mathrm{P}$ is observed with higher Sr substitution coatings. On day 5, $50 \%$ Sr-HA coating shows the disproportionate amount of $\mathrm{Sr}$ releasing relative to the $\mathrm{Sr}$ content in coatings. The ion releasing results also demonstrate the dissolution of coating. The coatings become more soluble with the elevation of the Sr content and the results are consistent with previous observations for $\mathrm{Sr}$ HA powders and SrCaP coatings. ${ }^{16,36} \mathrm{Ca}$ and $\mathrm{P}$ concentrations decrease with longer immersion time.

For $100 \%$ Sr-HA coatings, Pan et al. ${ }^{17}$ reported the highest solubility of fully substituted Sr-HA powders, while our study 

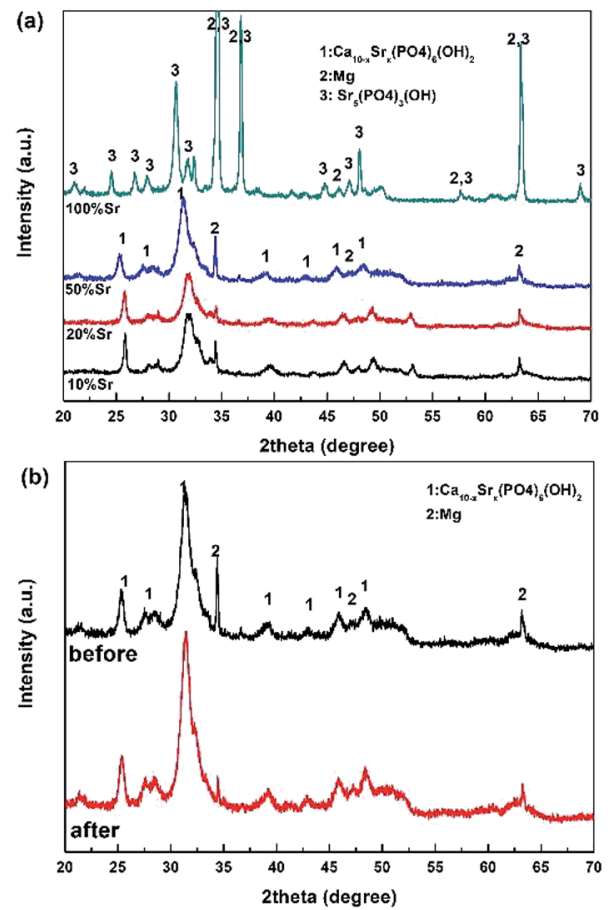

Fig. 7 (a) XRD patterns of the $\mathrm{Sr}-\mathrm{HA}$ coated $\mathrm{Mg}$ alloys after 10 d immersion in Hank's solution. (b) The comparison of the XRD patterns for $50 \% \mathrm{Sr}-\mathrm{HA}$ coated $\mathrm{Mg}$ alloys before and after immersion test.
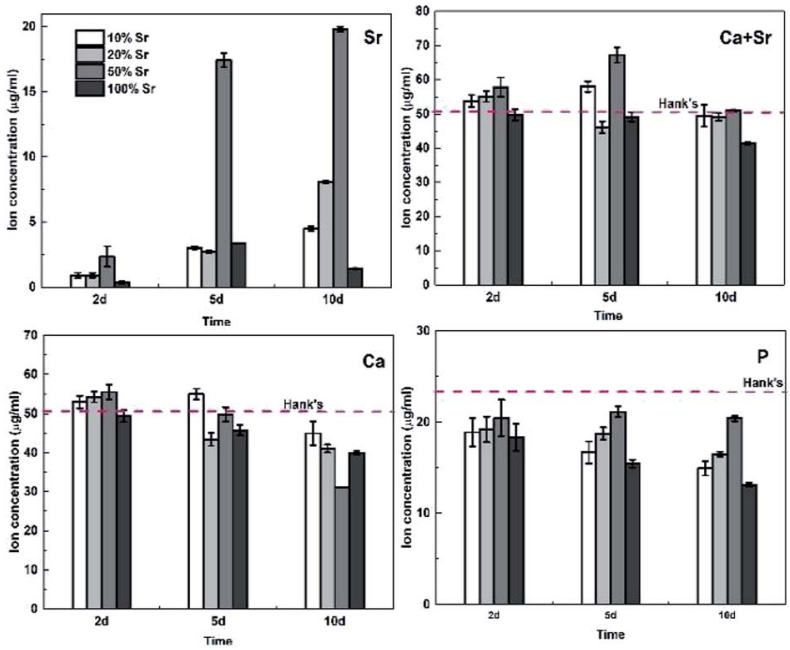

Fig. 8 The $\mathrm{Ca}$, Sr and $\mathrm{P}$ concentrations of the Hank's solution incubating with $\mathrm{Sr}-\mathrm{HA}$ coated $\mathrm{Mg}$ alloys for different time intervals.

indicated an opposite behavior. 100\% Sr-HA coatings exhibit the least Sr releasing during the immersion tests even with higher Sr content, which demonstrate its slowest dissolution rate. On the one hand, this could be interpreted by the less contamination of carbonate in $100 \%$ Sr-HA coatings (Fig. 2), which results in lower solubility. ${ }^{35,37}$ On the other hand, the high crystallinity also contributes to the highest corrosion resistance of $100 \%$ Sr-HA coatings.

\subsection{Degradation mechanism of Sr-HA coated $\mathrm{Mg}$ alloy}

The degradation of the Sr-HA coatings accelerates with increasing $\mathrm{Sr}$ content in the coatings up to $50 \%$. This is largely due to the larger ionic radius of $\mathrm{Sr}$, which typically results in an increase in the lattice parameters (Table 2) with higher levels of Sr substitution for Ca. Surprisingly, the more soluble $50 \% \mathrm{Sr}-\mathrm{HA}$ coatings show much better corrosion resistance than the coatings with lower degrees of Sr substitution. It can be explained by the dissolution and reprecipitation type mechanism of Sr-HA coatings. ${ }^{38,39}$ The schematic diagram is shown in Fig. 9. It begins with the surface dissolution of the Sr-HA coating when in contact with the corrosive media. $\mathrm{Ca}^{2+}, \mathrm{Sr}^{2+}$ and $\mathrm{PO}_{4}{ }^{3-}$ are released into the interface between coating and solution. Simultaneously, the corrosion of $\mathrm{Mg}$ cannot be completely restricted, which is largely due to the penetration of the corrosive media through the micro- and nano-pores in the coatings (see Fig. 4a) to the coating-Mg interface. This results in the instant dissolution of underlying $\mathrm{Mg}$ substrate with the generation of hydrogen gas (Fig. 5a) and $\mathrm{OH}^{-}$. This locally alkaline environment favors the apatite continuously precipitate back to the sample surface. ${ }^{23}$ As a consequence, the concentrations of $\mathrm{Ca}$ and $\mathrm{P}$ in Hank's solution decrease with longer immersion period (Fig. $8 \mathrm{c}$ and d) with the formation of a more compact coating morphology (Fig. 3). During this process, some micropores could be left in the original coatings or newly formed precipitation layer due to the hydrogen evolution from $\mathrm{Mg}$ substrate (Fig. 4c). This suggests that rapid coating dissolution may induce increased local release of $\mathrm{Ca}^{2+}, \mathrm{Sr}^{2+}$ and $\mathrm{PO}_{4}{ }^{3-}$, which readily leads to increased apatite formation ${ }^{7,40}$ to repair the dissolved coating, evidenced by the reduced concentration of $\mathrm{Ca}$ and $\mathrm{P}$ with longer immersion period (Fig. 8). The corrosion of Sr-HA coated $\mathrm{Mg}$ alloys is therefore suppressed. In the case of $100 \% \mathrm{Sr}-\mathrm{HA}$ coatings, the local release of multiple ions is less though, good apatite formation ability is observed. It is confirmed by the more rapid reduction of $\mathrm{Ca}$ and $\mathrm{P}$ concentrations in Hank's solution during the immersion period (Fig. 8), as compared to the $10-50 \%$ Sr-HA coatings. In addition, the newly formed cotton like precipitation (Fig. 3d2) with close $\mathrm{Ca} / \mathrm{P}$ ratio (1.59) to HA (Fig. 3f) also demonstrates the good mineralization ability. Fredholm et $a l^{40}$ also indicated enhanced apatite formation for $100 \%$ Sr substituted bioactive glass. ${ }^{40}$ The slowest degradation of $100 \% \mathrm{Sr}-\mathrm{HA}$ coated sample maybe attributed to both the slowly dissolution of the coating and the newly formed apatite. The degradation behavior of SrHA coating is a consequence of a number of different factors, while the level of $\mathrm{Sr}$ substitution is seen as highly significant considering its effect on the organization of HA lattice.

Table 2 The calculated unit cell parameters for $\mathrm{Sr}-\mathrm{HA}$ coatings

\begin{tabular}{llll}
\hline Sample & $a(\mathrm{~nm})$ & $c(\mathrm{~nm})$ & $V\left(\mathrm{~nm}^{3}\right)$ \\
\hline $10 \% \mathrm{Sr}$ & 0.9553 & 0.6882 & 0.5439 \\
$20 \% \mathrm{Sr}$ & 0.9594 & 0.6933 & 0.5526 \\
$50 \% \mathrm{Sr}$ & 0.9645 & 0.7056 & 0.5685 \\
$100 \% \mathrm{Sr}$ & 0.9747 & 0.7261 & 0.5974
\end{tabular}




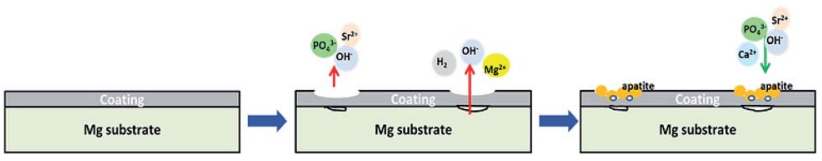

Fig. 9 Schematic diagram reveals the dissolution-precipitation of the $\mathrm{Sr}-\mathrm{HA}$ coating.

According to the obtained results in this study, it is obvious that the degradation of magnesium substrate can be regulated by controlling the degree of Sr incorporation in the Sr-HA coatings.

\subsection{Cell biocompatibility of Sr-HA coated $\mathrm{Mg}$ alloy}

The effects of Sr-HA coatings on the cell proliferation were investigated by exposure of the cells to $50 \%$ diluted extracts of the experimental samples. Fig. 10 reveals the osmolality, $\mathrm{pH}$ value and ion concentrations of the extracts. The extracts of $\mathrm{Sr}-$ HA coated samples exhibit significantly lower osmolality, $\mathrm{pH}$ value and $\mathrm{Mg}$ concentration than that of the uncoated samples. It shows no significantly difference in the three values of different $\mathrm{Sr}$-HA coated samples. While the $\mathrm{Sr}$ concentration in the extracts increases with increasing $\mathrm{Sr}$ content in the coatings up to $50 \%$. The Ca and P levels for all the samples are significantly lower than the DMEM control. Fig. 11 shows the metabolic activity tested by CCK- 8 assay and the ALP activity in different extracts. The cells show increased proliferation in the Sr-HA extracts. It reveals that cells cultured in four Sr-HA coating extracts exhibit relatively similar OD value until day 3 . The difference between the four groups become distinct at day 5 $(p<0.05)$ and OD value of the $50 \%$ Sr-HA coating extracts is significantly higher than the other three groups. The images of osteoblasts cultured in the extracts are shown in Fig. 11c to be consistent with the CCK-8 results. The cell ALP activity normalized to total protein show no significantly difference between four Sr-HA groups at day 3 and 5. Both the OD value and ALP activity of Sr-HA groups are higher than those of the uncoated one.

Osteogenic gene expression was also studied on Sr-HA coated samples to further analyse the capability of the coatings for enhanced differentiation (Fig. 12). The gene expression is normalized to that of cells cultured in the extracts of uncoated sample. Three osteogenesis markers, ALP (an early marker for osteogenic differentiation), RUNX2 (a key transcript factor for bone formation) and Col-1 (main content of bone ECM), were
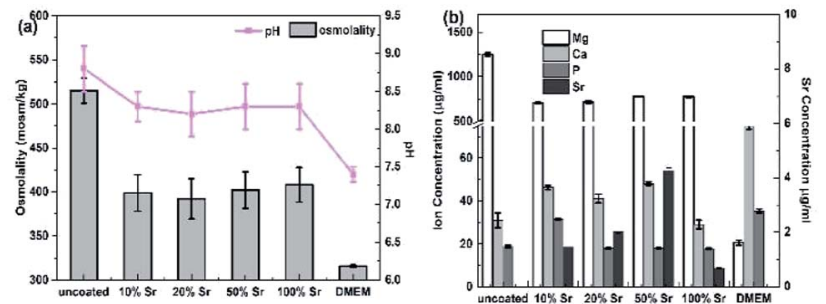

Fig. 10 (a) The osmolality, pH value and (b) ion concentrations of the extracts for the $\mathrm{Sr}-\mathrm{HA}$ coated Mg alloys.

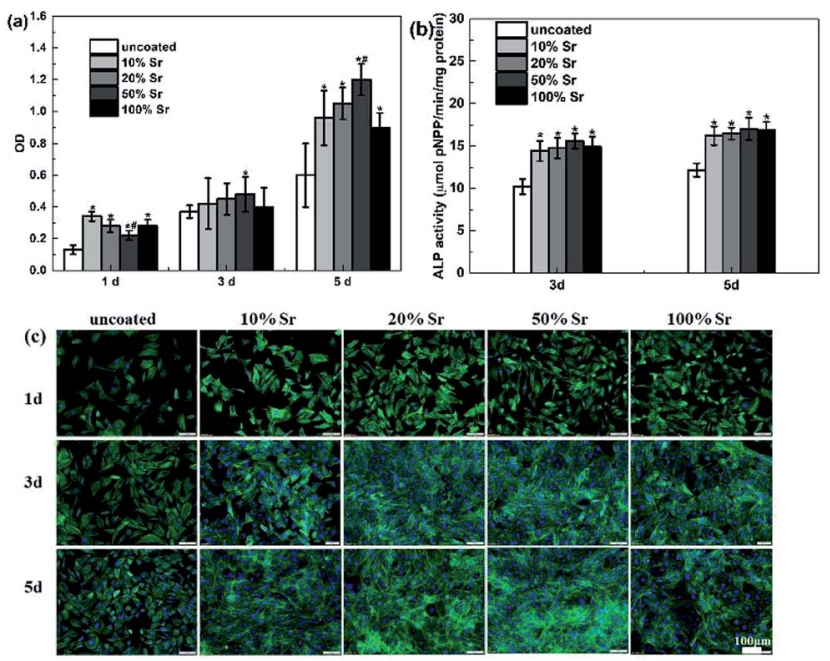

Fig. 11 Response of MC3T3-E1 osteoblasts to the extracts for Sr-HA coated Mg alloys, (a) CCK8 assay and (b) ALP activity. ${ }^{*} p<0.05$ vs. uncoated, $\# p<0.05$ vs. $10 \%$ Sr-HA. (c) Fluorescent images of MC3T3E1 osteoblasts cultured in the sample extracts.

tested. Higher ALP and Col-1 expression was observed for $20 \%$ Sr-HA coatings. A comparable RUNX2 expression was measured for $10-50 \%$ Sr-HA coatings. In addition, a distinct lower expression of Col-1, Runx2 and ALP was observed for $100 \% \mathrm{Sr}-$ HA coatings $(p<0.05)$.

The positive results of the Sr-HA coated samples can be explained by the following reasons. First, it is attributed to the slower corrosion and the resulted lower concentration of $\mathrm{Mg}$ in the extracts (Fig. 10). Wang et al. ${ }^{41}$ reported the combined effects of the loss of LTRPC7 function and the decrease of Ca involved binding sites/reactions in high $\mathrm{Mg}$ level, which may influence the cell viability. ${ }^{42} 10-15 \mathrm{mM}$ of $\mathrm{Mg}$ ion concentration is reported to be the critical dose without inhibiting cell viability. After $50 \%$ dilution, the concentration of $\mathrm{Mg}$ is approximately $15 \mathrm{mM}$ for Sr-HA coating extracts which is in the range of the biosafety level recommended in the previous study, ${ }^{41}$ while $26 \mathrm{mM}$ of $\mathrm{Mg}$ is observed for the uncoated samples. Second, the influence of Sr released from Sr-HA coatings cannot be excluded. The present study indicates that the osteoblast proliferation increases when treated with extracts containing higher Sr concentration and after longer incubation period. These results suggest a specific correlation between the Sr concentration in the extracts (Fig. 10b) and osteoblasts replication as well as osteogenic differentiation (Fig. 11a and

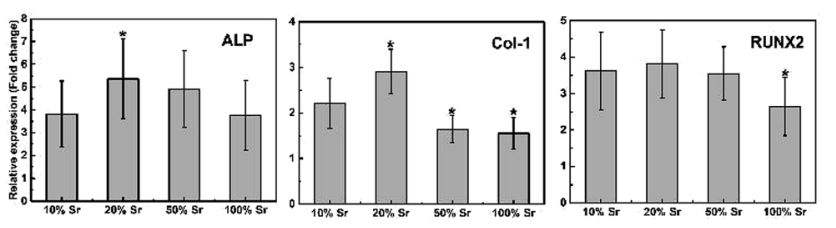

Fig. 12 Relative expression of Col-1, ALP and RUNX2 by MC3T3-E1 osteoblasts cultured in the extracts for $\mathrm{Sr}-\mathrm{HA}$ coated Mg alloys for $5 \mathrm{~d}$. $* p<0.05$ vs. $10 \% \mathrm{Sr}-\mathrm{HA}$. 
12). It is in line with the previously report that $\mathrm{Sr}$ is beneficial to osteoblast proliferation and osteogenesis in a dose dependent manner. ${ }^{22,40,43}$ Chen et $a .^{23}$ also found that $\mathrm{SrP}$ coated $\mathrm{Mg}$ exhibited better hMSC proliferation when extracts contained a higher concentration of Sr ions were used. From the preliminary data, it can be concluded that Sr content is an important parameter to adjust the solubility of Sr-HA coating and consequently regulate the degradation and biocompatibility of the SrHA coated $\mathrm{Mg}$ alloys. Future work will aim to assess the biocompatible mechanism of the Sr-HA coated $\mathrm{Mg}$ alloy using in vivo animal models.

\section{Conclusions}

In the current study, we have developed a series of Sr-HA coatings with various $\mathrm{Sr}$ contents on the surface of $\mathrm{Mg}$ alloy substrates. The results demonstrated that the degradation performance of the Sr-HA coated $\mathrm{Mg}$ alloys was significantly affected by the Sr content in the coatings. The degradation was reduced with increasing degree of $\mathrm{Sr}$ substitution in the Sr-HA coatings. $100 \%$ Sr-HA coated $\mathrm{Mg}$ alloys exhibited the slowest degradation performance as compared to the other samples. The MC3T3-E1 osteoblasts cultured in the extracts of Sr-HA coated $\mathrm{Mg}$ alloys were evaluated for their proliferation and differentiation responses. It revealed that improved cell proliferation and differentiation responses were observed due to the delayed $\mathrm{Mg}$ dissolution and $\mathrm{Sr}$ release from $\mathrm{Sr}-\mathrm{HA}$ coated $\mathrm{Mg}$ alloys. The present study suggests that $\mathrm{Sr}, x$-HA coating is a promising and effective option to control the degradation of $\mathrm{Mg}$ substrates, and the variation of $\mathrm{Sr}$ availability through dissolution influence the cell responses.

\section{Conflicts of interest}

There are no conflicts to declare.

\section{Acknowledgements}

This work was supported by the National Key R\&D Program of China (2018YFC1106600), a Foundation for the Author of National Excellent Doctoral Dissertation of PR China (201463), Young Elite Scientists Sponsorship Program by CAST (2017QNRC001) and NSFC (No. 11421202, 11827803), Beijing Natural Science Foundation (2192027).

\section{References}

1 J. Walker, S. Shadanbaz, B. F. Woodfield Timothy, P. Staiger Mark and J. Dias George, J. Biomed. Mater. Res., Part B, 2014, 102, 1316-1331.

2 Y. Zheng, X. Gu and F. Witte, Biodegradable metals, Mater. Sci. Eng. R Rep., 2014, 77, 1-34.

$3 \mathrm{~J}$. Ma, M. Thompson, N. Zhao and D. Zhu, JOT, J. Oberflaechentech., 2014, 2, 118-130.

4 X.-N. Gu and Y.-F. Zheng, Front. Mater. Sci. China, 2010, 4, 111-115.
5 D. Zhao, F. Witte, F. Lu, J. Wang, J. Li and L. Qin, Biomaterials, 2017, 112, 287-302.

6 N. T. Kirkland, N. Birbilis and M. P. Staiger, Acta Biomater., 2012, 8, 925-936.

7 N. Yu, S. Cai, F. Wang, F. Zhang, R. Ling, Y. Li, Y. Jiang and G. Xu, Ceram. Int., 2017, 43, 2495-2503.

8 T. M. Mukhametkaliyev, M. A. Surmeneva, A. Vladescu, C. M. Cotrut, M. Braic, M. Dinu, M. D. Vranceanu, I. Pana, M. Mueller and R. A. Surmenev, Mater. Sci. Eng., C, 2017, 75, 95-103.

9 Y. Su, D. Li, Y. Su, C. Lu, L. Niu, J. Lian and G. Li, ACS Biomater. Sci. Eng., 2016, 2, 818-828.

10 R. A. Surmenev, M. A. Surmeneva and A. A. Ivanova, Acta Biomater., 2014, 10, 557-579.

11 W. S. W. Harun, R. I. M. Asri, J. Alias, F. H. Zulkifli, K. Kadirgama, S. A. C. Ghani and J. H. M. Shariffuddin, Ceram. Int., 2018, 44, 1250-1268.

12 M. Emil Iskandar, A. Aslani and H. Liu, The effects of nanostructured hydroxyapatite coating on the biodegradation and cytocompatibility of magnesium implants, J. Biomed. Mater. Res. A, 2013, 101, 2340.

13 H. Tang and Y. Gao, J. Alloys Compd., 2016, 688, 699-708.

14 H. R. Bakhsheshi-Rad, E. Hamzah, A. F. Ismail, M. Aziz, A. Najafinezhad and M. Daroonparvar, J. Alloys Compd., 2019, 773, 180-193.

15 J. G. Acheson, S. McKillop, P. Lemoine, A. R. Boyd and B. J. Meenan, Materialia, 2019, 6, 100291.

16 W. Zhang, Y. Shen, H. Pan, K. Lin, X. Liu, B. W. Darvell, W. W. Lu, J. Chang, L. Deng, D. Wang and W. Huang, Acta Biomater., 2011, 7, 800-808.

17 H. B. Pan, Z. Y. Li, W. M. Lam, J. C. Wong, B. W. Darvell, K. D. K. Luk and W. W. Lu, Acta Biomater., 2009, 5, 16781685.

18 T. B. Ratnayake Jithendra, M. Mucalo and J. Dias George, J. Biomed. Mater. Res., Part B, 2016, 105, 1285-1299.

19 J. H. Shepherd, D. V. Shepherd and S. M. Best, J. Mater. Sci.: Mater. Med., 2012, 23, 2335-2347.

20 C. Li, Q. Yuan, L. He, Z.-J. Qian, C. Zhou and P. Hong, Coatings, 2019, 9, 141.

21 Q. Yuan, L. He, Z.-J. Qian, C. Zhou, P. Hong, Z. Wang, Y. Wang, S. Sun and C. Li, ACS Appl. Mater. Interfaces, 2018, 10, 30214-30226.

22 M. Frasnelli, F. Cristofaro, V. M. Sglavo, S. Dirè, E. Callone, R. Ceccato, G. Bruni, A. I. Cornaglia and L. Visai, Mater. Sci. Eng., C, 2017, 71, 653-662.

23 X. B. Chen, D. R. Nisbet, R. W. Li, P. N. Smith, T. B. Abbott, M. A. Easton, D. H. Zhang and N. Birbilis, Acta Biomater., 2014, 10, 1463-1474.

24 Y. Li, Q. Li, S. Zhu, E. Luo, J. Li, G. Feng, Y. Liao and J. Hu, Biomaterials, 2010, 31, 9006-9014.

25 E. A. Abdel-Aal, Inserting of strontium during coating of hydroxyapatite compound on titanium substrate, Int. J. Nanoparticles, 2011, 4, 77.

26 D. Guo, K. Xu, X. Zhao and Y. Han, Biomaterials, 2005, 26, 4073-4083.

27 G. X. Ni, W. W. Lu, K. Y. Chiu, Z. Y. Li, D. Y. T. Fong and K. D. K. Luk, J. Biomed. Mater. Res., Part B, 2005, 77, 409-415. 
28 Y. Lei, Z. Xu, Q. Ke, W. Yin, Y. Chen, C. Zhang and Y. Guo, Mater. Sci. Eng., C, 2017, 72, 134-142.

29 M. Avci, B. Yilmaz, A. Tezcaner and Z. Evis, Ceram. Int., 2017, 43, 9431-9436.

30 L. Robinson, K. Salma-Ancane, L. Stipniece, B. J. Meenan and A. R. Boyd, J. Mater. Sci.: Mater. Med., 2017, 28, 51.

31 A. R. Boyd, L. Rutledge, L. D. Randolph and B. J. Meenan, Mater. Sci. Eng., C, 2015, 46, 290-300.

32 A. R. Boyd, L. Rutledge, L. D. Randolph, I. Mutreja and B. J. Meenan, J. Mater. Sci.: Mater. Med., 2015, 26, 65.

33 A. Kaflak and W. Kolodziejski, J. Mol. Struct., 2011, 990, 263270.

34 Y. Wang, S. Von Euw, F. M. Fernandes, S. Cassaignon, M. Selmane, G. Laurent, G. Pehau-Arnaudet, C. Coelho, L. Bonhomme-Coury, M.-M. Giraud-Guille, F. Babonneau, T. Azaïs and N. Nassif, Nat. Mater., 2013, 12, 1144.

35 H. Pan and B. W. Darvell, Cryst. Growth Des., 2010, 10, 845850.
36 C. Lindahl, S. Pujari-Palmer, A. Hoess, M. Ott, H. Engqvist and W. Xia, Mater. Sci. Eng., C, 2015, 53, 322-330.

37 Q. Liu, J. P. Matinlinna, Z. Chen, C. Ning, G. Ni, H. Pan and B. W. Darvell, Ceram. Int., 2015, 41, 6149-6157.

38 J. Yan, J.-F. Sun, P. K. Chu, Y. Han and Y.-M. Zhang, J. Biomed. Mater. Res., Part A, 2013, 101, 2465-2480.

39 X. Niu, Y. Fan, X. Liu, X. Li, P. Li, J. Wang, Z. Sha and Q. Feng, Artif. Organs, 2011, 35, e119-e128.

40 Y. C. Fredholm, N. Karpukhina, D. S. Brauer, J. R. Jones, R. V. Law and R. G. Hill, J. R. Soc., Interface, 2012, 9, 880-889.

41 J. Wang, F. Witte, T. Xi, Y. Zheng, K. Yang, Y. Yang, D. Zhao, J. Meng, Y. Li, W. Li, K. Chan and L. Qin, Acta Biomater., 2015, 21, 237-249.

42 X. Gu, F. Wang, X. Xie, M. Zheng, P. Li, Y. Zheng, L. Qin and Y. Fan, Sci. China Mater., 2018, 61, 619-628.

43 X. Guo, S. Wei, M. Lu, Z. Shao, J. Lu, L. Xia, K. Lin and D. Zou, Int. J. Biol. Sci., 2016, 12, 1511-1522. 